\title{
Detection of HPV DNA in Cervical Carcinomas after Treatment in India
}

\author{
Ramdas Chatterjee, Biplab Mandal and Sarmistha Bandyopadhyay \\ Department of Viral Associated Human Cancer, Chittaranjan National Cancer Institute, \\ 37 S. P. Mukherjee Road, Kolkata 700 026, West Bengal, India
}

KEYWORDS Cancer treatment; cervical cancer; HPV; PCR

\begin{abstract}
Objective of this study was to evaluate the effect of treatment in eradicating HPV infection. We investigated presence of HPV DNAs in exfoliated cervical cells from cervical cancer patients before and after treatment. HPV DNA was detected by PCR using HPV consensus primers. HPV 16/18 were identified by PCR using type specific primers. HPV eradication was investigated after 3-8 months of treatment. Out of the 24 patients 4 were surgically treated and the rest by radiotherapy. HPV DNA was detected in $83.3 \%(20 / 24)$ of the patients before treatment. HPV types $16,18,16$ plus 18 and HPV types other than $16 / 18$ were demonstrated in $30 \%, 5 \%$, 35\%, and $30 \%$ of the patients. Following treatment $37.5 \%(9 / 24)$ of the patients were HPV positive. Results indicate that treatment may eradicate cervical HPV infection $(\mathrm{p}<0.001)$.
\end{abstract}

\section{INTRODUCTION}

Epidemiological evidences and laboratory studies have conclusively established association of some HPVs in developing cervical cancer (Bosch et al. 1995; Walboomers et al. 1999; zur Hausen 1994). Prevalence of HPV DNA of one or more of the greater than 20 genital types has been reported in $90-100 \%$ of cervical cancer cases (de Villiers 1989). HPV 16 and 18 are the most frequently detected types in cervical cancers (Howley 1991; zur Hausen 1991). Conflicting results are available on the relationship between specific HPV types and severity of the disease and prognosis. Some studies showed that compared to HPV 16 tumors, HPV 18 tumors are less differentiated and have more often nodal involvement (Barnes et al. 1988) and higher mortality (Walker et al. 1989). In contradiction, some studies observed no such association between HPV types and disease condition.

Radiotherapy is the most effective mode of treatment for cervical cancer. However, the factors controlling radiosensitivity of tumors are not clearly understood. Cervical carcinoma treatment is often characterized by local recurrence (3-8\% for stage I to $45 \%$ for stage III) (Hunter et al.

Address for correspondence: Dr. Ramdas Chatterjee, Department of Viral Associated Human Cancer, Chittaranjan National Cancer Institute, 37 S. P. Mukherjee Road, Kolkata 700 026, West Bengal, India Telephone: 913324765101

Fax: 913324757606

Email: ramdas@cal3.vsnl.net.in
1986). Tumor volume, stage, differentiation and lymph node involvement are possibly of prognostic significance (West 1995). Tumor proliferation index and expression of growth factors have been demonstrated to play a role in response of cervical cancer to radiotherapy (Morris GM, 1996; Pillai et al. 1998). Radiation response has also been associated with oncogene expression (Yarnold J, 1997). P53 status of tumor cells has been thought to play a great role in response to radiotherapy (Bristow et al. 1996; Kim et al. 1997). HPV may abrogate the functions of wild type p53 (Scheffner et al. 1990) and thus may influence radiosensitivity of the cervical tumors. Determination of HPV has been indicated to be useful predictor/prognostic marker (Friesland et al. 2001). However, not much study has been carried out to test efficacy of cervical cancer treatment on eradication of associated HPV infection.

In this study we investigated presence of HPV DNAs in exfoliated cervical cells from cervical cancer patients during pre and post treatment period. Our purpose was to evaluate the effect of treatment in HPV eradication and influence of the tumor stages.

\section{MATERIALSAND METHODS}

Sample Collection: Patients with invasive cervical cancer were recruited between December 1999 to June 2001 from Chittaranjan National Cancer Institute Hospital, Kolkata. The patients had histologically confirmed squamous cell carcinomas of uterine cervix and received no prior 
treatment for cancer. Stages of the disease were coded according to International Federation of Gynecology and Obstetrics. The staff of the Department of Gynecology and the Department of Radiology and Radiation Oncology analyzed staging. Only 24 patients could be followed-up for collecting cervical swabs for once 3-8 months after completion of treatment. Mean age of the patients while starting treatment was 50.33 years (range, 35-68 years).

Cervical exfoliated cells were collected in tubes containing PBS ( $\mathrm{pH} 7.4$ ), centrifuged and stored at $-80^{\circ} \mathrm{C}$ until analysis for HPV using consensus primer-based PCR (Resnick et al. 1990).

Treatment Techniques: Majority (20/24) of the follow-up patients was treated with radiation therapy alone. Remaining 4 (stage IB) requiring no postoperative radiotherapy underwent surgery. Under radiotherapy, the patients received external beam radiation of the entire pelvis and intracavitary brachytherapy irradiation (three fractions of high dose rate). Time from the start of radiation to completion was within 8 weeks. Telecobalt machine was used for external beam radiation therapy to apply a total dose of 50mgray (Gy) to the whole pelvis through antero-posterior and postero-anterior parallel opposite fields. A 2-Gy tumor dose at the midplane daily was the fraction size (five fractions every week). All patients did not receive irradiation for paraaortic lymph nodes. Intracavity irradiation was delivered with Co-60 and Ir-192. The dose of intracavity therapy was 8-Gy to Point-A weekly for 3 weeks. The first insertion was carried out when 20-Gy was administered to the pelvis. Next two insertions were performed weekly at the end of external beam radiation therapy. In other cases 3 intracavity insertions followed teletherapy. The dose rate at Point-A was more than 12-Gy per hour. The three brachytherapy fractions constituted a total dose of 24-Gy at Point-A.

DNA Isolation: Suspension of the exfoliated cervical cells in lysis buffer $(10 \mathrm{mM}$ Tris- $\mathrm{HCl}, \mathrm{pH}$ 7.5; 5mM EDTA, pH 7.9; $1 \%$ SDS) was treated with proteinase $\mathrm{K}(200 \mathrm{mg} / \mathrm{ml})$ overnight at $37^{\circ} \mathrm{C}$. High molecular weight DNA was prepared by phenol extraction followed by chloroformisoamyl alcohol (24: 1) extraction and ethanol precipitation. Concentration and quality of DNA were ascertained spectrophotometrically and by $0.8 \%$ agarose gel electrophoresis.

HPV Analysis by PCR: Overall presence of
HPV DNA was demonstrated by performing PCR with consensus primers derived from the E6 open reading frames. Amplifying a fragment of 240 base pairs the PCR permitted detection of a broad spectrum of genital HPV types (Resnick et al. 1990). PCR reaction and sample preparation were carried out in two different laboratories to avoid contamination. $\beta$-globin specific primers were used as amplification control for all samples (Resnick et al, 1990). Positive and negative controls were included during each amplification reaction. To identify the specific HPV types in the HPV positive specimens further PCR was performed using HPV 16 E6 and 18 E6 specific primers (product size: HPV 16: 109bp; HPV 18: 334bp) (Miller et al. 1994).

Each amplification reaction mixture (total volume of $25 \mu \mathrm{l}$ ) contained $10 \mathrm{mM}$ Tris. $\mathrm{HCl}, \mathrm{pH}$ $8.3,50 \mathrm{mM} \mathrm{KCl}, 1.5 \mathrm{mM} \mathrm{MgCl}, 200 \mathrm{mM}$ of each of dNTP, 100 pmoles of each primers, approximately $500 \mathrm{ng}$ of specimen DNA and 2.5 unit of thermostable DNA polymerase (Gibco BRL, USA). Amplification was carried out in the Thermal Cycler (Biorad, USA). After denaturation at $94^{\circ} \mathrm{C}$ for $3 \mathrm{~min}, 35$ cycles were used under following conditions for consensus primer mediated PCR: denaturation for $1 \mathrm{~min}$ at $94^{\circ} \mathrm{C}$, annealing at $55^{\circ} \mathrm{C}$ for $1 \mathrm{~min}$ and extension at $68^{\circ} \mathrm{C}$ for $2 \mathrm{~min}$ and a final 1 cycle extension at $72^{\circ} \mathrm{C}$ for 1 min. For HPV 16/18 specific PCR the first denaturation was performed at $95^{\circ} \mathrm{C}$ for $3 \mathrm{~min}$ followed by 30 cycles with denaturation at $95^{\circ} \mathrm{C}$ for $1 \mathrm{~min}$. The annealing conditions for HPV 16 , 18 were $55^{\circ} \mathrm{C}$ for $1 \mathrm{~min}$ and $54^{\circ} \mathrm{C}$ for $1 \mathrm{~min}$ respectively. The final extension cycle for $\mathrm{HPV}$ $16 / 18$ was performed at $72^{\circ} \mathrm{C}$ for $7 \mathrm{~min}$.

The PCR products $(10 \mu \mathrm{l})$ were electrophoresed in $1.8 \%$ agarose gel stained with ethidium bromide (Maniatis et al. 1982). The amplified products were identified by UV irradiation of the gels. The specimens showing PCR amplification products of the expected size were considered to be positive. Samples that were positive by PCR using consensus primers but could not be identified as HPV16 or 18 were considered as HPV X.

Following are the primer sequences used. HPV Consensus: Forward: 5' CGG TCG GGA CCG AAA ACGG 3'

Reverse: 5' AGC ATG CGG TAT ACT GTC TC 3' HPV 16: Forward - 5' ATT AGT GAG TAT AGA CAT TA 3'

Reverse-5' GGC TTT TGA CAG TTA ATA CA 3' 
HPV 18: Forward -5' ACT ATG GCG CGC TTT GAG GAT CCA 3'

Reverse-5' GGT TTC TGGCACCGCAGGCA3'

Statistical Analysis: Test of proportion was performed to evaluate significance of the treatment in HPV eradication.

\section{RESULTS ANDDISCUSSION}

Mean ages of the HPV-positive and -negative patients were 48.35 and 60.25 years respectively. Out of the 24 patients $83.3 \%(20 / 24)$ showed presence of HPV DNA in their cervical swabs before start of treatment. Table 1 shows that HPV DNA types $16,18,16$ plus 18 and ' $\mathrm{X}$ ' (other than 16/18) were present in 30\% (6/20), $5 \%$ $(1 / 20), 35 \%(7 / 20)$ and $30 \%(6 / 20)$ of the patients respectively. But at 3 to 8 months after the end of treatment $45 \%(9 / 20)$ of the HPV+ patients still remained positive. In the post-treatment test majority of the patients $6 / 9(66.6 \%)$ had double infection of HPV types 16 and 18 followed by HPV X type (2/9) and HPV 16 (1/9). But none had HPV 18 in the after treatment test. The 4 (4/24; $16.6 \%$ ) followed up cases that were HPV negative before treatment remained so even after treatment. Thus, HPV DNA was detected in 20/24 $(83.3 \%)$ patients before treatment and in $9 / 24$ $(37.5 \%)$ after the treatment. Test of proportion showed a significant $(Z=3.25 ; \mathrm{p}<0.001)$ reduction in HPV prevalence following treatment. The extent of eradication of HPV by the treatment varied with clinical stages of the patients. In stage IB it was brought down from $60 \%(3 / 5)$ to $20 \%(1 / 5)$, in IIB from $88.8 \%$ (8/9) to $44.4 \%$ (4/9) and in stage IIIB from $87.5 \%$ (7/8) to $37.5 \%$ (3/8). No particular HPV type was eradicated in preference to any other type. Out of the $6 \mathrm{HPV} 16$ positive patients 1 retained the same type, 2 became HPV 16/18 + and 3 had no HPV following treatment. HPV was eradicated by treatment from 3/7 HPV 16/18+, 4/6 HPV X+ and HPV 18 from the single patient. Thus gain in infection of additional HPV 18 was observed in 2 cases that were HPV 16+ before start of treatment.

In keeping with earlier reports (Higgins et al. 1991; Uchiyama et al. 1997) all the four HPV negative cervical carcinoma patients of this study belonged to higher age group (mean 60.25 years). Most of the patients of this study were treated by radiotherapy. However, in the United States chemotherapy administered concomitantly with radiation therapy is the currently accepted standard of care. Although a number of studies (Harima et al. 2002; Harima et al. 2001; Rantanen et al. 1998) have been carried out to analyze radiosensitivity of $\mathrm{HPV}+/ \mathrm{HPV}$ - sqamous carcinoma cell lines and survivability of HPV positive/negative cervical cancers treated with radiotherapy alone, very little observations have been made on the efficacy of the treatment in eradication of the virus. One group reported (Borrego et al, 2001) removal of HPV 18 (14.75\% cases) and HPV X (14.75\% cases) (HPV types 31 , $33,35,39,45,51,52)$ from all the cervical epidermoid carcinomas one month after radiotherapy. However, HPV 16 was not eradicated following treatment from $17.6 \%$ of the cases. We observed a significant $(\mathrm{p}<0.001)$ rate of HPV eradication (from $83.3 \%$ to $37.5 \%$ ) in our patients, though small in numbers, 3-8 months after treatment. However, it is possible that with longer follow-up HPV could be detected in the posttreatment HPV negative cases of this study.

In our study HPV 16 was not eradicated from $50 \%(3 / 6)$ of the patients. HPV X was removed from $43 \%$ (3/7) cases. Following treatment few of our HPV 16 patients acquired HPV 18 additionally. This is in agreement with a recent report (Liaw et

Table 1: HPV genotypes of the patients before and after treatment with respect to clinical stages.

\begin{tabular}{|c|c|c|c|c|c|c|c|c|c|}
\hline \multirow{3}{*}{$\begin{array}{l}\text { Clinical stages } \\
(N=24)\end{array}$} & \multicolumn{8}{|c|}{ HPV genotype } & \multirow{3}{*}{$\begin{array}{c}H P V \text { persistence } \\
\text { rate }(\%)\end{array}$} \\
\hline & \multicolumn{4}{|c|}{$\begin{array}{l}\text { Before treatment } \\
\text { (any positive }=20 \text { ) }\end{array}$} & \multicolumn{4}{|c|}{$\begin{array}{l}\text { After Treatment } \\
\text { (any positive }=9 \text { ) }\end{array}$} & \\
\hline & 16 & 18 & $16+18$ & $X$ & 16 & 18 & $16+18$ & $X$ & \\
\hline IB (5) & 1 & - & 1 & 1 & - & - & - & 1 & $1 / 3(33)$ \\
\hline IIB (9) & 3 & 1 & 2 & 2 & 1 & - & 2 & 1 & $4 / 8(50)$ \\
\hline IIIB (8) & 1 & - & 3 & 3 & - & - & 3 & - & $3 / 7 \quad(42)$ \\
\hline ND (2) & 1 & - & 1 & - & - & - & 1 & - & \\
\hline
\end{tabular}

ND $=$ Stage not detected

$\mathrm{X}=$ HPV types other than $16 / 18$ 
al. 2001) showing a general association of HPV 16 infection with greater risk of acquisition of other HPV types.

Persistence of HPV DNA in cervical cells has been reported after therapeutic conization for CIN3 (Nagai et al. 2000) and also after diathermic large loop excision treatment of CIN (Distefano et al.1998). In this study persistence of HPV infection after treatment was found to vary from $33 \%$ of patients in stage IB, $50 \%$ in stage IIB to $43 \%$ in stage IIIB. Survival rate of patients is known to decrease at advanced stage of the disease. Results of this study were indicative of greater rate of HPV persistence with reducing rate of survival of the patients. In this study HPV infection persisted in $42 \%$ (3/7) of the cases that were either HPV 16 or 18 positive before treatment. However, the persistence rate was higher $(56 \%$; 4/7) in the patients who had infections of multiple HPV types (16 and 18). This might have been possible owing to impairment of response of the patients to radiotherapy caused by the multiple type HPV infection. Eradication of the major causative infection of HPV is certainly the most effective long-term preventive measure and treatment profile may play an important role in this regard. Apart from the smaller number of study patients this investi-gation is limited by the nonexistence of survival data.

\section{REFERENCES}

Barnes W, Delgado G, Kurman RJ, et al. 1988. Possible prognostic significance of human papillomavirus type in cervical cancer. Gynecol Oncol, 29: 26773.

Borrego M, Soares P, Vasconselos A, et al. 2001. Identification of human papillomavirus in cervical carcinoma treated with radiotherapy. Abstr. (P-105) $19^{\text {th }}$ International Papillomavirus Conference, Florianopolis.

Bosch FX, Manos MM, Munoz N, et al. 1995. Prevalence of human papillomavirus in cervical cancer: a worldwide perspective. J Natl Cancer Inst, 87: 796802 .

Bristow RG, Benchimol S, Hill RP 1996. The p53 gene as a modifier of intrinsic radiosensitivity: implications for radiotherapy. Radiother Oncol, 40: 197223.

De Villiers EM 1989. Heterogeneity of the human papillomavirus group. J Virol, 63: 4898-903

Distefano AL, Picconi MA, Alonio LV, et al. 1998. Persistence of human papillomavirus DNA in cervical lesions after treatment with diathermic large loop excision. Infect Dis Obstet Gynecol, 6: 214219.

Friesland S, Mellin H, Munck-Wikland E, et al. 2001. Human papillomavirus (HPV) and p53 immunostaining in advanced tonsillar carcinoma - relation to radiotherapy response and survival. Anticancer Res, 21: 529-534.

Harima Y, Sawada S, Nagata K, et al. 2002. Human papillomavirus (HPV) DNA associated with prognosis of cervical cancer after radiotherapy. Int J Radiat Oncol Biol Phys, 52: 1345-1351.

Harima Y, Sawada S, Nagata K, et al. 2001. Chromosome 6p21.2, 18q21.2 and human papillomavirus (HPV) DNA can predict prognosis of cervical cancer after radiotherapy. Int J Cancer, 96: 286-296.

Higgins GD, Davy M, Roder D, et al. 1991. Increased age and mortality associated with cervical carcinomas negative for human papillomavirus RNA. Lancet, 338: 910-913.

Howley PM 1991. Role of the human papillomaviruses in human cancer. Cancer Res, 51: 5019s-5022s.

Hunter RD, Cowie VJ, Blair V, et al. 1986. A clinical trial of two conceptually different radical radiotherapy treatments in stage III carcinoma of the cervix. Clin Radiol, 37: 23-27.

Kim HE, Han SJ, Kasza T, et al. 1997. Platelet-derived growth factor (PDGF)-signaling mediates radiationinduced apoptosis in human prostate cancer cells with loss of p53 function. Int $J$ Radiat Oncol Biol Phys, 39: 731-736.

Liaw KL, Hildesheim A, Burk RD, et al. 2001. A prospective study of human papillomavirus (HPV) type 16 DNA detection by polymerase chain reaction and its association with acquisition and persistence of other HPV types. J Infec Dis, 183: $8-15$.

Maniatis T, Frisch EF, Sambrook J (Eds.) 1982. Molecular Cloning. New York: Cold Spring Harbor, Cold Spring Harbor Laboratory.

Miller CS, Zeuss MS, White DK 1994. Detection of HPV DNA in oral carcinoma using polymerase chain reaction together with in situ hybridization. Oral Surg Oral Med Oral Pathol, 77: 480-486.

Morris GM 1996. Effects of radiation on the cell proliferation kinetics of epithelial tissuestherapeutic implications. Brit J Radiol, 69: 795803.

Nagai Y, Maehama T, Asato T, et al. 2000. Persistence of human papillomavirus infection after therapeutic conization for CIN 3: is it an alarm for disease recurrence? Gynecol Oncol, 79: 294-299.

Pillai MR, Jayaprakash PG, Nair MK 1998. Tumor proliferative fraction and growth factor expression as markers of tumor response to radiotherapy in cancer of the uterine cervix. J Cancer Res Clinical Oncol, 124: 456-461.

Rantanen V, Grenman S, Kurvinen K, et al. 1998. p53 mutations and presence of HPV DNA do not correlate with radiosensitivity of gynecological cancer cell lines. Gynecol Oncol, 71: 352-358.

Resnick RM, Cornelissen MT, Wright DK, et al. 1990. Detection and typing of human papillomavirus in archival cervical cancer specimens by DNA amplification with consensus primers. J Natl Cancer Inst, 82: 1477-1484.

Scheffner M, Wereness BA, Huibregtse JM, et al. 1990. The E6 oncoprotein encoded by human papillomavirus type 16 and 18 promotes the degradation of p53. Cell, 63: 1129-1136.

Uchiyama M, Iwasaka T, Matsuo N, et al. 1997. 
Correlation between human papillomavirus positivity and p53 gene overexpression in adenocarcinoma of the uterine cervix. Gynecol Oncol, 65: 23-29.

Walboomers JM, Jacobs MV, Manos MM, et al. 1999. Human papillomavirus is a necessary cause of invasive cervical cancer worldwide. J Pathol, 189: $12-19$.

Walker J, Bloss JD, Liao SY, et al. 1989. Human papillomavirus genotype as a prognostic indicator in carcinoma of the uterine cervix. Obstet Gynecol, 74: 781-785.
West CM. 1995. Intrinsic radiosensitivity as a predictor of patient response to radiotherapy. Brit J Radiol, 68: $827-837$

Yarnold J 1997. Molecular aspects of cellular responses to radiotherapy. Radiother Oncol, 44: 1-7.

Zur Hausen H 1994. Molecular pathogenesis of cancer of cervix and its causation by specific human papillomavirus types. Curr Top Microbiol Immunol, 186: $131-135$.

Zur Hausen H 1991. Viruses in human cancers. Science, 254: $1167-1173$. 